\title{
Place as Assemblage: Abstracting, Diagramming and Mapping
}

\author{
By Milica Muminovic ${ }^{*}$
}

\begin{abstract}
Place is an ambiguous concept denoting various elements of the environment, both built and natural. There are a number of different philosophical approaches which examine the notion of place including those that focus on the morphology of the built environment and those deriving from phenomenology. However, most of the theories agree that place is more than what we can see, more than just a built environment and we can summarise the complexity of the built and social environments into one aspect and quality that we call place identity. Different theories generate divergent methods for analysing place. Most approaches, however, develop an objective map of a place in which the subjective data are ignored. For this reason, this paper explores analyses that use subjectivity as a tool and asks to what extent the latter is effective in analyses of place? The intent of this paper is not to fully discard the objective mapping of place but to discuss other methods that can be used to fully understand its complexity. The paper also tests the effectiveness of the diagrammatic approach in place mapping. The definition of the diagram, which derives from both architecture and philosophy, is largely based on Vidler's theoretical explorations overlapped with the definition of the diagram from assemblage theory. The paper highlights two case studies which use diagramming as a mapping process for understanding place. Streets in Tokyo and Canberra are examined to see how objective data could be visualised to generate an objective or subjective place diagram. The paper argues that diagrammatic mapping involves a level of abstraction that is then read in ways that differ from the intentionality of the author. Thus, a diagram allows the process of layering subjective information during which reading becomes distanced from the original intention, standing as a pure visualisation that can transmit the feeling or the atmosphere and capture the complexity of a place.
\end{abstract}

\section{Introduction}

There are various philosophical approaches to defining place which contribute to the ambiguity of the concept. Different viewpoints on place derive from a range of disciplines interested in built environments. In addition to the various definitions of place, there are even more diverse attempts to analyse it. Some explore place from an objective and quantifiable perspective and are interested in large scales over long periods of time, for example urban morphology. ${ }^{1}$ There are also those that focus more on the social aspects of place and urban grain. Others attempt to understand place through observations of peoples' behaviour. ${ }^{2}$

All these approaches endeavour to objectively observe, visualise and

\footnotetext{
*Assistant Professor, University of Canberra, Australia.

1. M. R. G. Conzen, "Urban morphology: a geographical approach," in Thinking about urban form (ed.) M. R. G. Conzen (Oxford, New York: Peter Lang, 2004), 145-48.

2. J. Gehl and B. Svarre, How to study public life (Washington, Covelo, London: Island Press, 2013).
} 
represent place. Objectivity is important for understanding the environment, however, it does not exhaust the scope and complexity of a place. ${ }^{3}$ If place is defined as something more than simple built form, then the analysis should aim to capture those aspects of place. Furthermore, it could be argued that to understand a place in its full complexity we need all these approaches to layer the data in order to come closer to a full description.

In addition to the complexity of defining place, another challenging aspect of its analysis is the concept of the spirit of the place or "genius loci." Ways to describe the spirit of a place are largely subjective. ${ }^{5}$ Each person defines her or his place. There have been some attempts to incorporate this subjectivity as part of the definition of place. Most prominent are those using the urban diary method ${ }^{6}$ which notes and describes experiences in the city. These are captured as anectdotal explorations rather than visual and mapped experiences. The diary method is based on individual observations of the city and not on multiple subjectivities. There are also approaches where mapping relies on the creation of situations ${ }^{7}$ to generate different understanding of a place. The aim in this case is to understand aspects of everyday life and ordinary perspectives, thus including a different kind of subjectivity as part of the selection process for the case study.

There have also been attempts to synthesize various analyses of place in order to generate a more complete understanding of it. One of these is a composite method that includes observations, interviews, diary and mapping techniques. ${ }^{8}$ The approach consists of de-layering methods of analysis to understand various aspects of place, which are then re-layered in a map to decode a reality in a new way.

Most analysis of place is based on a number of mapping techniques. Mapping as a tool for analysis is not a simple representation of reality but has certain levels of abstraction and editing. The visualized elements in a map are carefully selected and displayed. The fact that maps are using the process of dissecting reality helps us understand the relationships between various elements in the map and read reality in a different way. Even the way in which elements are presented on the map define the direction of the reading and understanding of a place. Thus, each map contains a level of abstraction and subjectivity. Most often this process is based on the abstraction of objective data. However, there is no analytical approach based on mapping that aims to capture the subjective aspects of place. Therefore, the aim of this paper is to explore the diagram as a device to visualize and map the subjective experience of a place as analytical tool. The objective is to discuss whether the process of abstraction, that is inherently subjective, could be

3. D. Radovic, Subjectivities in Investigation of the Urban: The Scream, the Shadow and the Mirror (Tokyo: flick Studio, 2014).

4. C. Norberg-Schulz, Genius loci: towards phenomenology of architecture (New York: Rizzoli International Publications, 1980).

5. P. Lefas, Dwelling and Architecture - From Heidegger to Koolhaas (Berlin: Jovis Verlag $\mathrm{GmbH}, 2009)$.

6. C. R. Wolfe, Seeing the Better City. How to Explore, Observe, and Improve Urban Space (London: Island Press, 2017).

7. S. Sadler, The Situationist City (Cambridge: MIT Press, 1999).

8. M. Sepe, Planning and Place in the City. Mapping place identity (London and New York: Routledge, 2013). 
used as one of the tools to study place.

The first part of the paper summarises the definitions of place. The definition of place is related to subjective aspects including feelings, personal memory, and knowledge and presents a context for, and understanding of, why subjectivity is a significant element of analysis. Place is defined as a dynamic concept that derives from assemblage theory. Secondly, the definition of a diagram, and its applicability in analyses, is outlined using Anthony Vidler's theoretical explorations inherited from architecture and overlain with assemblage theory. Since place is defined as an assemblage and introduces the aspect of change, the same approach is applied to the definition of the diagram. Assemblage theory is largely based on materialism ${ }^{9}$ and does not necessarily focus on subjectivities, however, it is an important attempt to avoid rigidity in the phenomenology and frames the analysis of place in its complexity. ${ }^{10}$ Thus, definitions of both place and diagram are derived from assemblage theory and already established definitions that introduce aspects of subjectivity. Finally, two tests of the diagramming process are explained. The outcomes of those processes are used to discuss abstraction as a tool to understand the subjective aspects of place.

\section{Place as Assemblage}

There are two main philosophical approaches to place. One derives from phenomenology and it is explored in the work of Norberg-Schultz who appropriated the definitions from Heidegger's discussions on Being. According to this approach, a place is defined as a phenomenon that is constructed based on our experience of the built environment. ${ }^{11}$ The space is experienced through our senses, however, that experience is never a simple perception. ${ }^{12}$ It always includes our own understandings, knowledge, moods and feelings within that experience. Thus, place emerges through conscious and subconscious experiences and not from a simple observation, "...there is no place without self and no self without place." ${ }^{\prime 3}$ As part of that experience, subjectivity is an important element and is manifested through feelings and thoughts. ${ }^{14}$

The subjectivity mentioned in definitions of place does not necessarily refer to the individuality of experiences. Individual experiences can never be separated from the community or collective definitions of place. Public images of place are constructed over time through consensus between different groups of people. Some places have a strong identity or sense of history, others do not. There are

9. G. Deleuze, Difference and Repetition (New York: Columbia University Press, 1994), 222.

10. M. Muminovic, "Places as Assemblages: Paradigm Shift or Fashionable Nonsense?" Athens Journal of Architecture 1, no. 4 (2015): 295-309.

11. Norberg-Schulz, Genius Loci: Towards Phenomenology of Architecture, 1980.

12. J. Pallasmaa, The eyes of the skin, Architecture and the senses (Chichester: Wiley, 2012).

13. E. S. Casey, "Between Geography and Philosophy: What does it mean to Be in the PlaceWorld?" Annals of the Association of American Geographers 91, no. 4 (2001): 684.

14. Y. Tuan, Space and place: the perspective of experience (Minneapolis: The University of Minnesota Press, 1977), 6. 
also mass images around the experience of place as a result of mass media. ${ }^{15}$ Thus, there is a kind of layering of individual experiences which create objective, public and common understandings of place. It could be argued that those experiences are complex, consisting of both individual and collective, or public perceptions of place.

Furthermore, the understanding of a place is built over time. Time and place are interrelated through practices as a framework for experiences. ${ }^{16}$ To define a certain location as a place, we need time to experience that location, to get to "know" it. Visual characteristics of location are easy to grasp, however, to feel and to generate meaning we need longer and more exhaustive experiences of the location. ${ }^{17}$ However, the fact that time has passed, and people have experienced a certain location, does not mean that they have been appropriating it as a place. There are locations that do not leave deep impressions on people and never become a place.

Place is thus a dynamic category that changes over time. However, all past experiences remain active memory fragments of present experiences. Those memories create meanings that we individually assign to a location that is emerging in interaction with the "world." " The meanings are bound to the physicality of a location, and at the same time are elements of subjective personal meanings that are shared through collective understandings of place.

In recent years, there is another approach which has emerged to define place. It is based on assemblage theory and aims to overcome elements of phenomenology and essentialism ${ }^{19}$ and define place in its full complexity. Within this approach, place is an assemblage, an entity which recognises its non-linearity. The definition focuses on the relationship between elements. Assemblages are wholes whose properties emerge from the relationships between parts. ${ }^{20}$ Those relationships comprise interiority and exteriority interactions; thus, assemblage is not a simple sum of its parts.

Instead of permamence, place as assemblage focuses on change over time. Multiplicity is an important aspect of place and defines place through processes and change. The morphogenetic aspects of place are important for outlining "spaces of possibilities." 21 The place then is in a constant state of change that is becoming. ${ }^{22}$ The past and present are part of becoming in which past "has not

15. E. Relph, Place and placelessness (London: Pion Limited, 1986).

16. K. Lynch, What time is this place? (Massachusetts and London: The MIT Press Cambridge, 1972), 241.

17. Relph, Place and placelessness, 1986.

18. Norberg-Schulz, Genius Loci: Towards Phenomenology of Architecture, 1980, 170.

19. K. Dovey, Becoming Places, Urbanism/Architecture/Identity/Power (London and New York: Routledge, 2010).

20. M. Delanda, A New Philosophy of Society-Assemblage Theory and Social Complexity (London and New York: Continuum, 2006), 5.

21. M. Delanda, Intensive Science and Virtual Philosophy (London and New York: Continuum, 2002), 10.

22. G. Deleuze and F. Guattari, A Thousand Plateaus Capitalism and Schizophrenia. (trans.) B. Massumi (Minneapolis: University of Minnesota Press, 1987). 
ceased to be. ${ }^{, 23}$ Multiplicity replaces the essence that denotes the constancy of any place and represents a framework that guides the change. ${ }^{24}$ Place is observed as a dynamic set of processes that emerge from intensity. The difference in intensities is an important aspect of the individualisation processes of any place. ${ }^{25}$ Furthermore, individualisation is based on the morphogenetic processes that can be divided into two groups: intensive and extensive properties. The difference between intensive and extensive magnitude is based on divisibility, the former being indivisible and the latter, divisible. ${ }^{26}$ In physics, those qualities could be described using the example of a room. If we divide the room into two, the volume of the room will represent the extensive property, as it is divided into two halves, but the temperature of the air might be considered as intensive property as it did not change upon the division. Some examples of intensive properties are related to emotions and thus are subjective aspects: joy, love, hate, grief, beliefs, desires, and so forth. In the definition of place, extensive properties are defined as measurable, objective or tangible and intensive properties refer to the subjective aspects of place.

For this paper, assemblage theory is applied in discussions of the complexity of place and defines it as a changing entity. By generating relationships between various descriptions, we arrive at a more comprehensive understanding of place. In this sense, both subjective and objective elements become part of the analysis. In addition, the idea of capturing the intensive aspects of place, those that are highly subjective, provides a basis for a more complete definition of place.

\section{The Diagram}

'Diagram' has in recent decades become a popular term that is used not only to describe an analytical tool, but also a method of design and a kind of architecture (for example Toto Ito's characterization of Kajuyo Sejima's architecture as diagrammatic). The common ground for the proliferation of diagram in architecture results from the increasing production of digital technologies. Those techniques are defined as "digital experiments" in morphological studies. ${ }^{27}$ Diagrammatic architecture is a term that is used to criticize the simplicity of modern architecture. ${ }^{28}$

The etymological meaning of the word diagramma derives from both Latin and Greek, and signifies something that is symbolised, figured, traced, written or

23. G. Deleuze, Bergsonism (trans.) H. Tomlinson and B. Habberjam (New York: Zone Books, 1991), 51.

24. Delanda, Intensive Science and Virtual Philosophy, 2002, 59.

25. Deleuze, Difference and Repetition, 1994.

26. M. Delanda, "Space: Extensive and Intensive, Actual and Virtual," in Deleuze and Space (ed.) I. Buchanan and G. Lambert (Edinburgh: Edinburgh University Press, 2005), 80-88.

27. A. Vidler, "Diagrams of Diagrams: Architectural Abstraction and Modern Representation" Representations 72 , no. 5 (2000).

28. Ibid, 8. 
drawn, thus something that is visualised. ${ }^{29}$ The word is composed of the Greek dia, meaning across or between the two and gramma that defines a figure, line or mark. ${ }^{30}$ Diagrams differ from simple representations of the object because they depict only selected aspects of the reality of the original object and also denote relationships. Diagrams could be defined as being both real and ideal, objective and subjective, reductive and generative. ${ }^{31}$ Thus, the way in which diagrams are read or interpreted has an important layer of subjectivity.

Diagrams have a long history of development in architecture including the nine-square, the Panopticon, the Dom-ino, and Rudolf Wittkower's diagrams of the Palladian Villas from 1949. In modern architecture, drawings show an increasing tendency to depict abstract objects stripped from decorative elements, which leads to criticism that it reduces complexity and is oversimplifying and alienating. Diagrams differ from simple drawings. They are not only an analytical tool but are used as a projective device that emphasizes the virtual rather than the real. ${ }^{32}$ Because of these characteristics, diagrams are often part of the design and link to the drawing. The idea of drawing as imagining, or as a process of production of architecture, was abstracted to a diagram in Modernism and today is completely dissolved with the advent of new technologies. ${ }^{33}$

Diagrams in assemblage theory are also not simple visualising tools but represent the characteristics of morphological processes inherent in the material world. ${ }^{34}$ This approach opposes essentialist perspectives that attempt to define the essence of the object to be visualised with the diagram. Thus, instead of having only one essence that represents a place, in assemblage theory there are multiple ways of describing and visualising a place. This process merges objective and subjective within a number of potential diagrams as a visualising device of a layered reality.

Since diagrams focus on the processes and relationships between various elements-not only those that are existing (describing) but also potential relationships (multiplicities) - they could be considered to be the best means to engage with the complexity of the real. ${ }^{35}$ While defining the semiotics, Peirce explains an important aspect of diagrams. ${ }^{36}$ For Peirce, diagrams mark the internal and external relations of their objects in abstract mode. Thus, they are useful devices for thinking, as they reduce the number of details and allow the mind to focus on important features. The abstraction as creative process includes

29. M. Garcia, "Histories and Theories of the Diagrams of Architecture," in The Diagrams of Architecture (ed.) M. Garcia (Chichester: Wiley, 2010), 22.

30. A. Vidler, "What is a Diagram Anyway?" in Peter Eisenman Feints (ed.) S. Cassara (Milan: Skira Editore, 2006), 16.

31. Ibid, 25.

32. Vidler, Diagrams of Diagrams: Architectural Abstraction and Modern Representation, $2000,16$.

33. Ibid.

34. M. Delanda, "Deleuze, Diagrams, and the Genesis of Form," Amerikanstudien/American Studies 45, no. 1 (Chaos/Control: Complexity, 2000), 34.

35. S. Allen, "Diagrams Matter," in Diagram Work, no. 23 (ed.) B. van Berkel and C. Bos (New York: Anyone Corporation, 1998), 17.

36. M. Arnold, "Images, diagrams, and narratives: Charles S. Peirce's epistemological theory of mental diagrams," Semiotica 186, no. 1 (2011). 
permutation and transformation. ${ }^{37}$ Diagrams emerge in the process of selective abstraction that reduces reality to a concept of phenomenon. ${ }^{38}$ Furthermore, diagrams are abstractions that represent phenomena by focusing on spatial relationships. ${ }^{39}$ In Modernism, abstraction is considered to be an "aesthetic quality." relations within elements and their surroundings. However, diagrams are not realistic representations of relationships, they only indicate spatial relationships. ${ }^{41}$

Diagrams also represent a range of moments in the state of the object, where its elements are in various conditions of equilibrium, ${ }^{42}$ opposed to the idea of seeking the essence, which is the only one ideal state. Those are defined as "diagrammatic spaces of energetic possibilities." 43 Diagrams are not representations of the form and the "real." They are not only an abstraction but "representation of something in that it is not a thing itself," 44 "neither substance nor form, neither content nor expression." 45 Diagrams should be distinguished from signs, images and drawings. Image reproduces a particular thing whilst diagrams focus more on a functional articulation of a thing ${ }^{46}$ and they are a "real yet to come, a new type of reality.",47

The diagram is abstract and is not a visual archive, rather, Deleuze refers to it as cartography, as a map. "It is an abstract machine." 48 Furthermore, in assemblage theory diagrams are spatio-temporal multiplicities. "The diagram or abstract machine is the map of relations between forces, map of density, or intensity, which proceeds by primary non-localizable relations and at every moment passes through every point, or rather in every relation from one point to another." 49 According to Deleuze, diagrams also represent change, they do not signify persisting aspects of the entity but generate a new kind of reality. Even though Deleuze refers to the diagram as a map that defines relationships, the application of the diagram for analysis in urban scales is underexplored. This paper therefore discusses aspects of the usage of the diagram as a mapping technique.

37. A. Vidler, "What is a Diagram Anyway?" in Peter Eisenman Feints (ed.) S. Cassara (Milan: Skira Editore, 2006), 20.

38. Garcia, Histories and Theories of the Diagrams of Architecture, 2010, 18.

39. E. Yi-Luen Do and M. Gross, "Thinking with Diagrams in Architectural Design," Artificial Intelligence Review 15, no. 136 (2001).

40. Vidler, Diagrams of Diagrams: Architectural Abstraction and Modern Representation, 2000, 20.

41. Yi-Luen Do and Gross, "Thinking with Diagrams in Architectural Design," 2001, 137.

42. Delanda, "Deleuze, Diagrams, and the Genesis of Form," 2000, 34.

43. Ibid.

44. P. Eisenman, Diagram Diaries (London: Thames and Hudson, 1999), 27.

45. Deleuze and Guattari, A Thousand Plateaus: Capitalism and Schizophrenia, 1987, 141.

46. G. Genosko, The Guattari Reader (Oxford: Blackwell Publishers Ltd., 1996), 17.

47. Deleuze and Guattari, A Thousand Plateaus: Capitalism and Schizophrenia, 1987, 142.

48. G. Deleuze, Foucault (trans.) S. Hand (London: The Athlone Press, 1988), 34.

49. Ibid, 36. 


\section{Method: Diagrams and Place}

Explorations of place are generally visualised through maps. Maps are drawings that aim to represent reality, define orientation and objectively transmit space. On the other hand, definitions of place suggest that there is an important aspect of that reality that is defined through experience and intensity, as well as through potential and existing, interior and exterior relationships. The brief summary of the literature around the diagram defines it as a device that merges the real and the virtual, describing an entity not through its presentation but through potential relationships and multiplicities. This indicates that one of the most important aspects of the diagram is abstraction and the fact that the diagram is not a simple representation of reality. This is the main difference between the map, traditionally used to analyse place, and the diagram as a potential tool that can represent any entity. A map always refers to an actual reality, whereas a diagram does not necessarily represent the actual space. Diagrams visualise only certain characteristics or the relationships within an entity. In addition, the aspect of abstraction, and thus subjectivity in the diagram, is present not only at the level of generating a diagram, but also at every next reading of it. Thus, in this paper, subjectivity is captured during two steps: the process of generating the diagram and its reading.

Since diagrams derive from abstraction processes, there is no singular reading of diagrams. ${ }^{50}$ This includes the "reading" of diagram within individual processes that further enhance layering of multiple subjectivities. In addition, diagrams describe not only the current reality but also the potential states of the entity, virtual spaces, and therefore capture the emerging aspects of the place which are in constant change.

Based on the literature review of the definitions of place and diagram we can outline similarities that demonstrate the importance of utilising diagrams in analysis of place. Those similarities are summarised below using three main aspects of place (Table 1).

Table 1. Comparison of Characteristics of Place and Diagram

\begin{tabular}{|c|c|c|}
\hline place & diagram & characteristic \\
\hline $\begin{array}{c}\text { subjective intensive } \\
\text { properties }\end{array}$ & abstraction & $\begin{array}{c}\text { defining only partial and } \\
\text { different representation of place }\end{array}$ \\
\hline complex & relationships & $\begin{array}{c}\text { layering of interiority and } \\
\text { exteriority relationships }\end{array}$ \\
\hline emerging & multiplicity & $\begin{array}{c}\text { there is no single state but } \\
\text { multiple and potential states }\end{array}$ \\
\hline
\end{tabular}

To test the application of the diagram for analysis of place the author uses two case studies: one approach merges objective and subjective processes whilst the other explores diagram based entirely on subjectivity. The former case focuses the physical aspects of the place and transforms the objective observations from the space into subjective experience based intensity. The

50. Allen, "Diagrams Matter," 1988, 20. 
abstraction is applied in the second stage of the analysis by removing the direct link to the visual aspects of reality (in this example the street). The latter case represents a different approach in which abstraction is present from the beginning of the analysis. The whole process is subjective. There is a layering of subjectivity at the stage of understanding a place and subjectivity is incorporated as part of "reading" the diagram. Comparing the two different approaches to the analysis of place, the paper discusses the levels of abstraction and subjectivity and how these contribute to our understanding.

\section{Results: Diagramming the Place}

The first case study explores the mechanism of abstraction of real, measurable data to visualise experience in the street. The analysis focuses on the presence of ephemeral objects in the narrow roji (alleyways) in Tokyo's Nezu district. The diagrams developed compare the quantity and distribution of ephemeral objects along the streets and reveal the intensity and sense of domesticity. Because of the density and size of the blocks and streets, and the presence of personal belongings as ephemeral elements on the street, it has been argued that narrow lanes in Tokyo contain a unique experience of traditional character. Due to the small spaces in apartments and houses, the alleyway is considered as a semi-public, semi-private space appropriated by the residents. This appropriation manifests as small potted plants and personal belongings revealing traces of inhabitation. The atmosphere is experienced while walking through the streets and is three-dimensional when including the alleyway as a whole. The aspects of the built environment that affect the experience include the size of the streets, their openness and closeness, as well as ephemeral objects. Mapping the elements would not reveal the whole experience but only the quantity of the objects. Therefore, the proposed abstraction technique focuses on capturing and comparing the character of the streets by distribution of those ephemeral elements in three-dimensional space, and when time is included, in four-dimensional reality. The focus of the analysis is on the experience of familiarity and the domestic atmosphere in the small alleyways in Tokyo.

The first stage of analysis captures data from the field, taking photos and mapping ephemeral elements. Photos are taken along the streets both due to their narrowness (these streets are 1-2 $\mathrm{m}$ wide) and because it is the most effective way to capture the presence of the objects. Because the streets are so narrow it is impossible to capture the façade of the building. Once photos are taken every $7.5 \mathrm{~m}$ along the street (determined to be the most appropriate distance to note changes in scenery), the elements are mapped, and the quantity of visual coverage is measured (Figure 1). The measurement used is the coverage of pixels as a percentage. Based on the scale of coverage of ephemeral objects, classes are created with each photograph corresponding to one section of the stripe. This generates a coded stripe that shows only the distribution of the density of ephemeral elements. At this stage, abstraction has completely separated the information on the stripe from the real space by generating a diagram. Once the 
process of abstraction has transformed the actual experience of the street to the stripe, based on the unifying and objective principle of classification, the diagram can be reinterpreted in various ways. Using this diagram, a greater number of streets are compared in order to understand the whole neighbourhood (Figure 2). In this case, the stripes are an abstracted experience of the density of ephemeral objects along the alleyways, but visually have no connection to the real space. The visualization is based on real data and the whole process reduces subjectivity to a minimum. The intensity of the experience of domesticity is read through the constant change in the density of ephemeral objects.

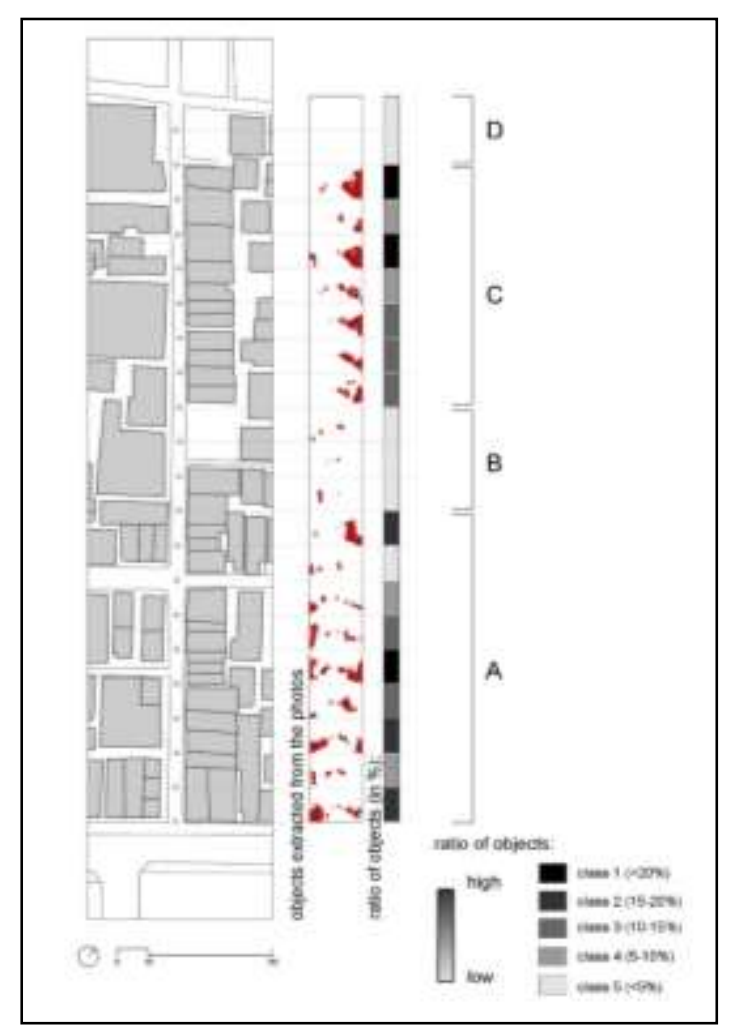

Figure 1. Diagramming Process of a Roji in Tokyo Source: Author, 2013.

The comparative analysis of streets has shown that there is diversity in the presence of ephemeral objects along the street. This diversity amplifies the experience of the domestic as there is constant discovery and change from a range of almost no ephemeral elements, to many. This is how the intensity of the experience has been created: within difference and repetition (figure 2).

The second example starts with abstraction and focuses largely on subjectivity. The aim was to discover how people experience Canberra's public spaces through their quality and connectedness. ${ }^{51}$ Canberra is a planned and highly car dependant city. Public spaces are mainly natural open public spaces or interior

51. This project is a result of work undertaken in the honours thesis by Nathan Paulleto: "Communicating the Incommunicable" 2016, funded by a grant from the Early Career Academic Research Development Program at the University of Canberra. 
privately owned public spaces (PoPs). Understanding the quality of the street is challenging, as pedestrian movement is limited and traditional methods of behavioural and spatial analysis was found not to be effective for understanding the potential hidden quality of the places. Thus a different method was applied that included abstraction and subjectivity in order to discover the place's potential.

highest values of ephemeral elements:

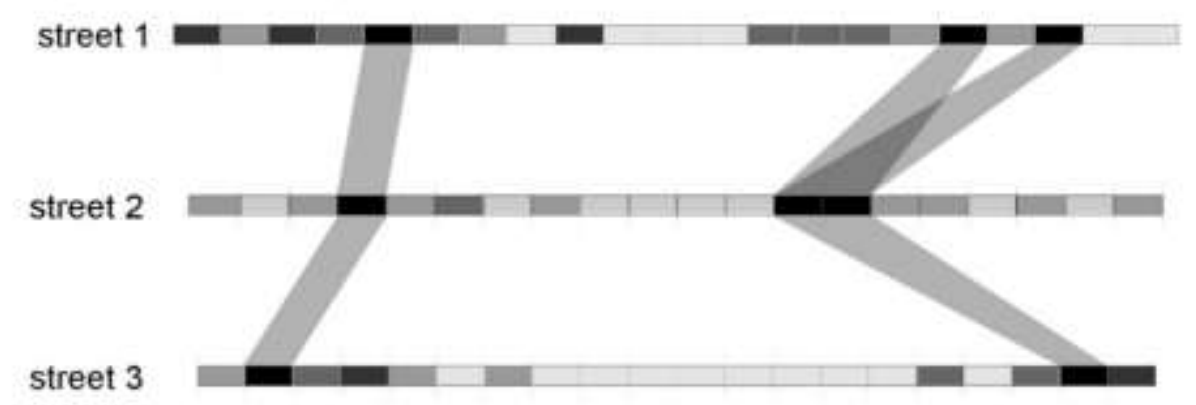

lowest values of ephemeral elements:

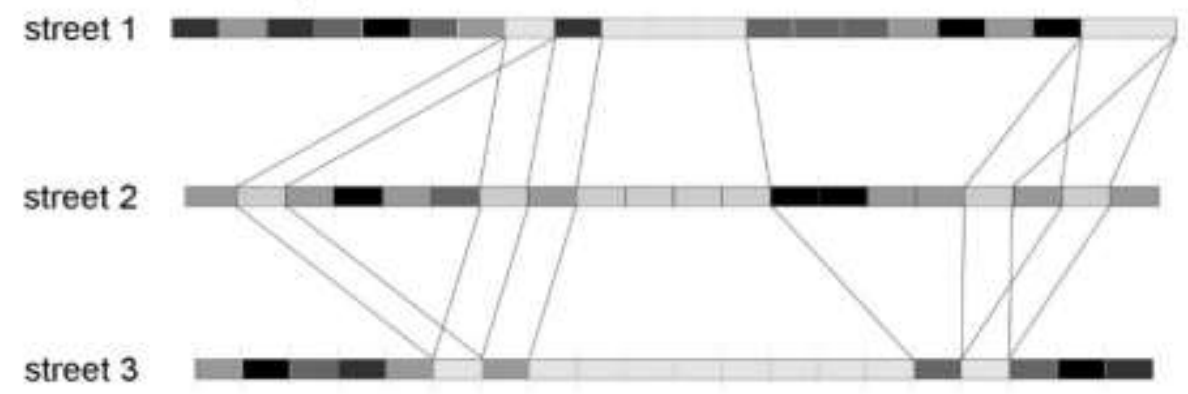

Figure 2. Comparison of the Stripes along Three Streets in Nezu Source: Author, 2013.

The first step undertaken in the project was to transform the real map of Canberra into an abstract grid of points (Figure 3). The rationale for doing this was that each viewer could reinterpret the map individually and subjectively. Thus, the abstraction process took place at the beginning of analysis. The map was abstracted to a number of points and their density simulated the density of the built environment. In order to generate multiple subjectivities, an interactive activity was created using a board that asked people to weave their regular and favourite routes in the city, with a little guidance on how to "read" the abstract map of Canberra. Each person interpreted the scale of the map based on his or her memory and experience. Once each person finished weaving the places, they were asked to explain the map. After the diagram was overlaid with the real map, the analysis of differences revealed how people's experiences created a new, distorted map of the intensities of spaces (Figure 4). The gravitational points in real space 
and fields of intensity demonstrated relationships and the sense of place (Figure 5). In this case, the mapping of Canberra began with objective data that represents Canberra, a map. This map was transformed into an abstract grid and finally the reflection on collective weaving represents the subjective reading of multiple subjectivities. Standing alone, without interpretation, this map is an abstract image that could be read from many different angles.

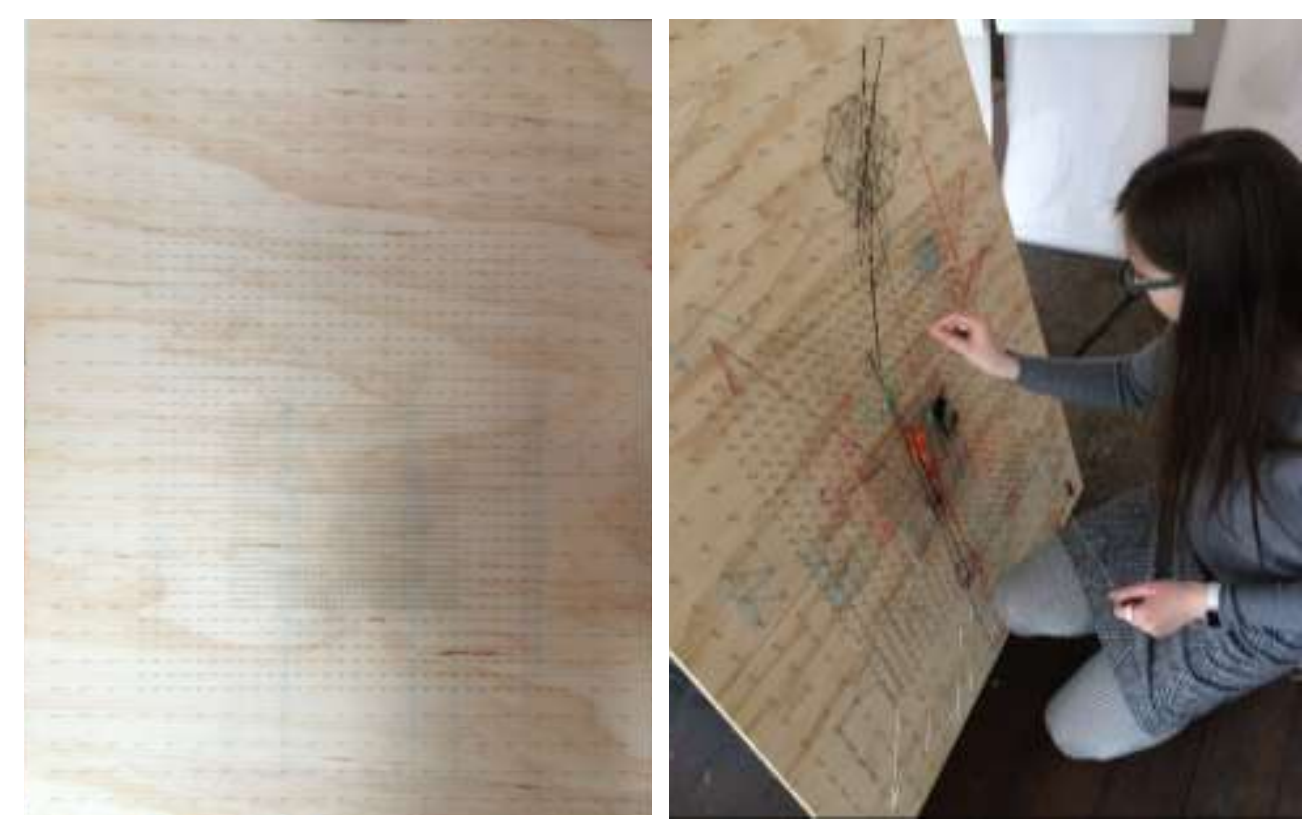

Figure 3. Interactive Board as the Beginning of Mapping Process
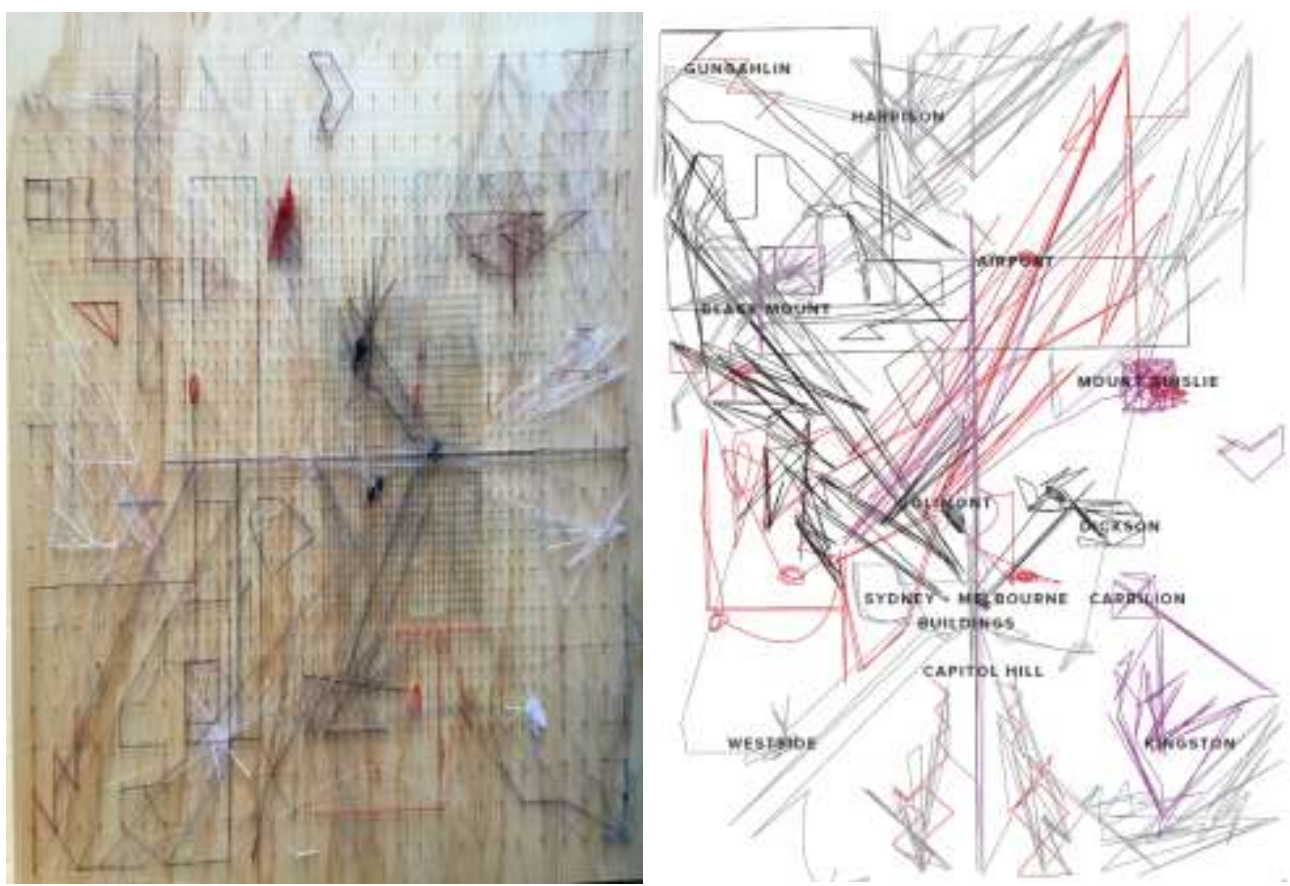

Figure 4. Transforming the Abstract Map to the Real Space Map

Source: Pauletto and Muminovic, 2016. 


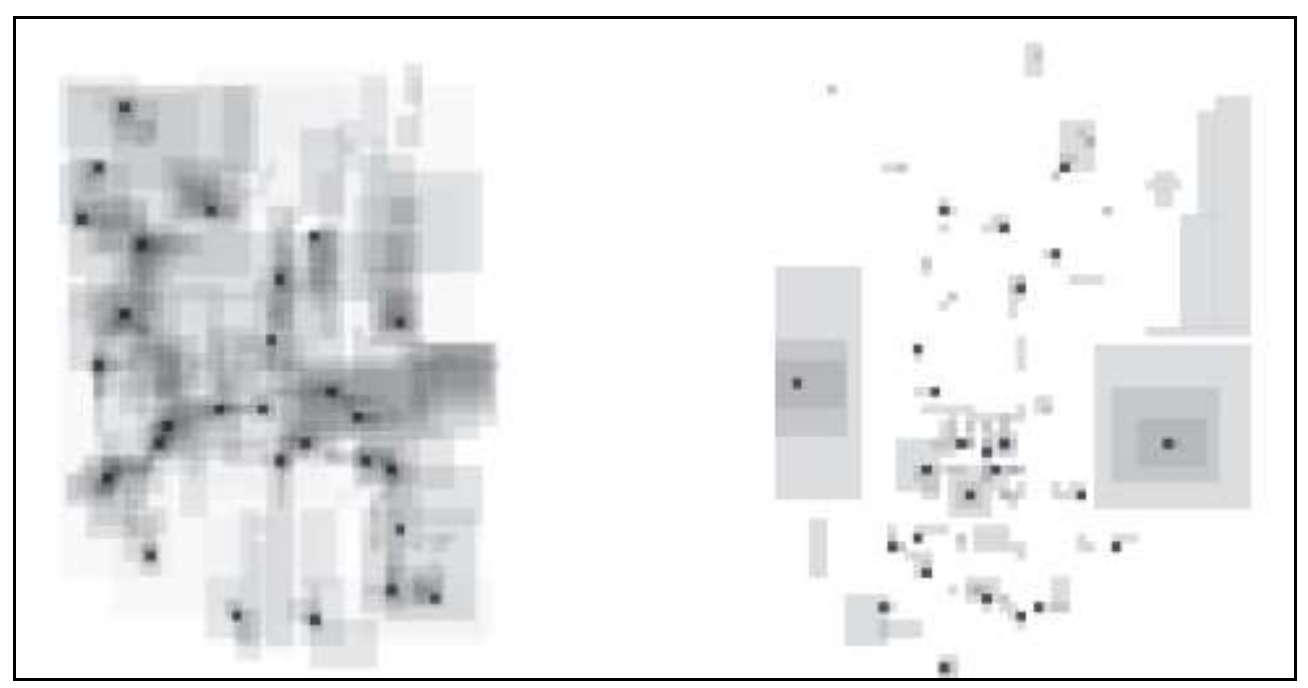

Figure 5. Transformation of Collective Data and Reinterpretation (left: Reinterpretation of Collective Diagram; right: Reinterpretation of Actual Spaces on the Map)

Source: Pauletto and Muminovic, 2016.

\section{Discussion: The Process of Abstraction}

Through the process of abstraction, each case study has revealed different information about the place in question that could not be revealed within the limits of traditional mapping techniques. In the case of Nezu, the analysis confirmed that ephemeral elements on the streets create the sense of domesticity. More importantly, these diagrams have demonstrated how that process actually emerges. The relationship between various elements in the street generates dynamic experiences while walking along the roji and because of the changes in density of ephemeral objects there is a constant sense of surprise - thus the presence of these ephemeral elements becomes amplified (Figure 1 shows the zones of high and low density of ephemeral elements through sections A-B-C-D). The actual number of elements differs from the experience of their size and quantity. The diagrams also reveal relationships between those elements. The diagrams do require decoding in order to read them, however they clearly show the quality of the space based on the intensity of ephemeral elements. This characteristic follows on from Deleuze's definition of the intensive properties of place that define its atmospheric qualities and subjective experiences.

On the other hand, the Canberra's case study demonstrates the challenge within the second stage of the reading process. The final diagram is reinterpreted in a different manner as it demonstrates the character of the spaces and their connections. The process has revealed that the visualising method of abstraction creates a state in which reading the intensity is experienced differently. The main result of the analysis focuses on the fact that our perception of relationships between places demonstrates more connectedness than is present in reality (Figure $5)$. 


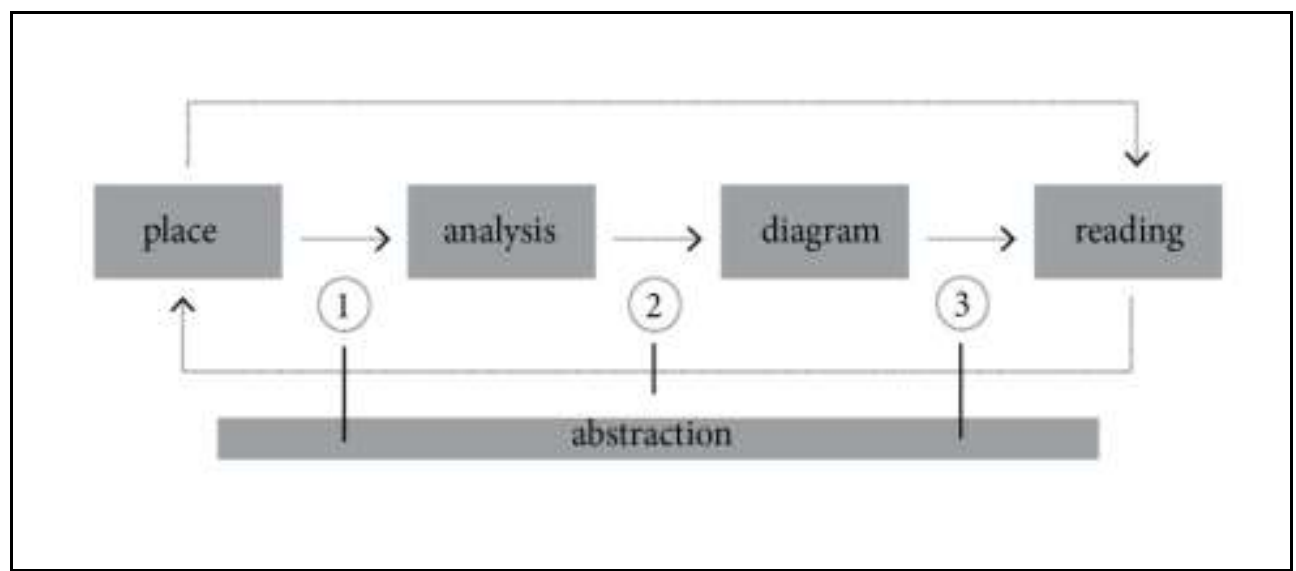

Figure 6. The Process of Abstraction in Diagramming the Place

Source: Author, 2018.

The two cases of mapping have shown that depending on how and in which stage of the analysis the abstraction process is applied, it will generate various levels of subjectivity (Figure 6). In the Tokyo case study, the process is clear because diagrams are generated based on the measurable and objective data which is produced in stage (2). Although after the abstraction there is no direct link to the actual space, it is still comprehensible as the spatial quality of the streets in Nezu. On the other hand, in Canberra's case abstraction is introduced in the early stage of the analysis (1) and the whole process deliberately reduces the sense of scale. Thus, although generated with the layering of subjectivities, the whole process multiplies abstraction and has little connection to the real space. In this case, the link between the actual space and the diagram is difficult to follow. The final reading of the diagram varies. Every reading of the diagram introduces another level of subjectivity, as each person needs to restore the link to actual space and thus re-imagine the urban quality, a sense of constant becoming.

The abstraction in the case of Nezu is organised according to one spatial dimension, whilst the abstraction in Canberra is two-dimensional. Namely, the linearity of the street in Nezu is followed through into the shape of the diagram but in Canberra's case the abstraction is based on two-dimensions and the reference points in real space are difficult to follow.

\section{Conclusions}

Virtual elements are present in both Vidler's and Deleuze's definition of diagram and are an important part of the subjectivity required to understand a place. The virtual elements are not real; however, they are possible as they are generated through individual readings of either the place itself or in the relationship between the place and its experience. Although assemblage theory does not discuss experience as part of the definition of a diagram, this is evident as an important element in both case studies and is interpreted through the intensive properties of place. Differences in the density of the built environment are confirmed to generate intensity of experience. The intensity emerges over time in 
the relationship between densities.

The "misreading" of an abstracted map or a diagram might be considered a potential tool to explore the meaning of a place, with every next reading involving a new layer of subjectivity. The place diagram grows through countless layers of readings and the meaning of place emerges in between those readings. This element explores the place as becoming. The analysis has also shown that the element of abstraction also becomes the element of arbitrary manipulation. However, this process enhances the subjectivity of understanding the place. Each individual reading of the diagram and map adds another layer of subjectivity and multiplying subjectivities in addition to objective data, define the place in its complexity. Thus, multiplicity in a diagram is generated any time there is a new reading of the exiting diagram.

The question of the stage at which abstraction should be used needs further exploration. As a method, abstraction in diagrams has shown that it provides a good base for a subjective reading of a place: thus it is one aspect to be included in the readings of place, not as an independent analysis.

\section{Acknowledgements}

The author is immensely grateful to Nathan Paulleto and his visualising explorations that have largely inspired the arguments for diagramming processes in mapping.

\section{Bibliography}

Allen, S. "Diagrams Matter." In Diagram Work, no. 23. Edited by B. van Berkel and C. Bos. New York: Anyone Corporation, 1998, 16-23.

Arnold, M. 2011. "Images, Diagrams, and Narratives: Charles S. Peirce's Epistemological Theory of Mental Diagrams." Semiotica 186, no. 1 (2011): 5-20.

Casey, E. S. "Between Geography and Philosophy: What Does it mean to be in the Placeworld?" Annals of the Association of American Geographers 91, no. 4 (2001): 68393.

Conzen, M. R. G. "Urban Morphology: A Geographical Approach.” In Thinking About Urban Form: Papers on Urban Morphology, 1932-1998. Edited by M. R. G. Conzen. Oxford, New York: Peter Lang 2004. Reprint, Annual Report of Whitby Literary and Philosophical Society.

Delanda, M. "Deleuze, Diagrams, and the Genesis of Form." Amerikanstudien/American Studies 45, no. 1, Chaos/Control: Complexity, 2000.

Delanda, M. Intensive Science and Virtual Philosophy. London and New York: Continuum, 2002.

Delanda, M. "Space: Extensive and Intensive, Actual and Virtual." In Deleuze and Space. Edited by I. Buchanan and G. Lambert. Edinburgh: Edinburgh University Press, 2005, 80-88.

Delanda, M. A New Philosophy of Society - Assemblage Theory and Social Complexity. London and New York: Continuum, 2006.

Deleuze, G. Foucault. Translated by S. Hand. London: The Athlone Press, 1988. 
Deleuze, G. Bergsonism. Translated by H. Tomlinson and B. Habberjam. New York: Zone Books, 1991.

Deleuze, G. Difference and Repetition. Translated by P. Patton. New York: Columbia University Press, 1994.

Deleuze, G. and F. Guattari. A Thousand Plateaus: Capitalism and Schizophrenia. Translated by B. Massumi. Minneapolis: University of Minnesota Press, 1987.

Dovey, K. Becoming Places, Urbanism/Architecture/Identity/Power. London and New York: Routledge, 2010.

Eisenman, P. Diagram Diaries. London: Thames and Hudson, 1999.

Garcia, M. "Histories and Theories of the Diagrams of Architecture." In The Diagrams of Architecture. Edited by M. Garcia. Chichester: Wiley, 2010.

Gehl, J. and B. Svarre. How to Study Public Life. Washington, Covelo, London: Island Press, 2013.

Genosko, G. (ed.) The Guattari Reader. Oxford: Blackwell Publishers Ltd, 1996.

Lefas, P. Dwelling and Architecture- from Heidegger to Koolhaas. Berlin: Jovis Verlag $\mathrm{GmbH}, 2009$.

Lynch, K. What Time Is This Place? Massachusetts and London: The MIT Press Cambridge, 1972.

Muminovic, M. "Places as Assemblages: Paradigm Shift or Fashionable Nonsense?" Athens Journal of Architecture 1, no. 4 (2015): 295-309.

Norberg-Schulz, C. Genius Loci: Towards Phenomenology of Architecture. New York: Rizzoli International Publications, 1980.

Pallasmaa, J. The Eyes of the Skin, Architecture and the Senses. Chichester: Wiley, 2012.

Paulleto, N. and M. Muminovic. Communicating the Incommunicable, Understanding Public Space through Creative Method/Visualisation of Memory. Canberra Urban Synergies Group, 2016.

Radovic, D. Subjectivities in Investigation of the Urban: The Scream, the Shadow and the Mirror. Tokyo: flick Studio, 2014.

Relph, E. Place and Placelessness. London: Pion Limited, 1986.

Sadler, S. The Situationist City. Cambridge: MIT Press, 1999.

Sepe, M. Planning and Place in the City. Mapping Place Identity. London and New York: Routledge, 2013.

Tuan, Y. Space and Place: The Perspective of Experience. Minneapolis: The University of Minnesota Press, 1977.

Vidler, A. "Diagrams of Diagrams: Architectural Abstraction and Modern Representation." Representations 72 (2000): 1-20.

Vidler, A. "What Is a Diagram Anyway?" In Peter Eisenman Feints. Edited by S. Cassara. Milan: Skira Editore, 2006.

Wolfe, C. R. Seeing the Better City. How to Explore, Observe, and Improve Urban Space. London: Island Press, 2017.

Yi-Luen Do, E. and M. Gross. "Thinking with Diagrams in Architectural Design." Artificial Intelligence Review 15 (2001): 135-49. 